\title{
Power calibration methodology at the CROCUS reactor
}

\author{
Vincent Lamirand $^{1,2 *}$, Axel Laureau ${ }^{1}$, Oskari Pakari ${ }^{1}$, Pavel Frajtag ${ }^{1}$, Andreas Pautz ${ }^{1,2}$ \\ ${ }^{1}$ Ecole Polytechnique Fédérale de Lausanne (EPFL) \\ ${ }^{2}$ Nuclear Energy and Safety Research Division (NES), Paul Scherrer Institut (PSI) \\ *vincent.lamirand@epfl.ch
}

\begin{abstract}
In the present article, we detail the method used to experimentally determine the power of the CROCUS zero-power reactor, and to subsequently calibrate its ex-core monitor fission chambers. Knowledge of the reactor power is a mandatory quantity for a safe operation. Furthermore, most experimental research programs rely on absolute fission rates in design and interpretation - for instance, tally normalization of reaction rate studies in dosimetry, or normalization of power spectral density in neutron noise measurements. The minimization of associated uncertainties is only achieved by an accurate power determination method. The main experiment consists in the irradiation, and therefore, the activation of several axially distributed Au-197 foils in the central axis of the core, which activities are measured with a High-Purity Germanium (HPGe) gamma spectrometer. The effective cross sections are determined by MCNP and Serpent Monte Carlo simulations. We quantify the reaction rate of each gold foil, and derive the corresponding fission rate in the reactor. The variance weighted average over the distributed foils then provides a calibration factor for the count rates measured in the fission chambers during the irradiation. We detail the calibration process with minimization of respective uncertainties arising from each sub-step, from power control after reactivity insertion, to the calibration of the HPGe gamma spectrometer. Biases arising from different nuclear data choices are also discussed.
\end{abstract}

Index Terms-Neutron dosimetry, neutron activation analysis, in-core dosimetry, integral experiment, zero-power reactor

\section{INTRODUCTION}

$\mathrm{T}$ HE CROCUS reactor is a two-zone, uranium-fuelled light water moderated facility operated by the Laboratory for Reactor Physics and Systems Behaviour (LRS) at the Swiss Federal Institute of Technology Lausanne (EPFL). With a maximum power of $100 \mathrm{~W}$, it is a zero-power reactor used for teaching and research purposes, most recently for studies on intrinsic and induced neutron noise, highly-localized measurements, and nuclear data [1]-[19]. Knowledge of the reactor power is a mandatory quantity for a safe operation. Furthermore, most experimental research programs rely on absolute fission rates for design and interpretation [20] - for instance, tally normalization of reaction rate studies in dosimetry, or normalization of power spectral density in neutron noise measurements. The minimization of associated uncertainties is only achieved by an accurate power determination method. We present hereafter the method used to determine the reactor power and to subsequently calibrate the ex-core monitor fission chambers [21]-[23]. The main experiment consists in the irradiation, and therefore, the activation of several axially distributed ${ }^{197} \mathrm{Au}$ foils in the central axis of the core, which activities are measured with a HPGe gamma spectrometer. The effective cross sections are determined using MCNP6.1 [24] and Serpent2 [25] Monte Carlo simulations. We quantify the reaction rate of each gold foil, and derive the corresponding fission rate in the reactor. The variance weighted average over all foils then provides a calibration factor for the count rates measured in the fission chambers during the foil irradiation. We detail the calibration process with minimization of respective uncertainties arising in each sub-step, from power control after reactivity insertion, to the calibration of the HPGe gamma spectrometer. Biases arising from different nuclear data choices are also discussed.

\section{EXPERIMENTS}

In this part we briefly present CROCUS, the methodology and experimental setup for foil activations and measurements, and the dedicated experimental campaign.

\section{A. The CROCUS reactor}

A complete description of the reference core of CROCUS is available in the International Reactor Physics Experiments Handbook (IRPhE) [26], [27]. The reactor has been licensed for operating at a maximum power of $100 \mathrm{~W}$, i.e. a total neutron flux of $\sim 2.5 \cdot 10^{9} \mathrm{~cm}^{-2} \cdot \mathrm{s}^{-1}$ at the core center. Criticality is controlled either by water level using a spillway, or by two $\mathrm{B}_{4} \mathrm{C}$ absorber control rods, with an accuracy of $\pm 0.1 \mathrm{~mm}$ (equivalent to approximately $\pm 0.4 \mathrm{pcm}$ ) and $\pm 0.5 \mathrm{~mm}$ (up to $\pm 0.2 \mathrm{pcm}$ ), respectively. CROCUS operates at a core temperature from $17.5^{\circ} \mathrm{C}$ to $22.5^{\circ} \mathrm{C}$ using a controlled water loop with secondary and tertiary circuits, two heat exchangers and an electrical heater.

The core is located in an Al-6060 grade open vessel of $130 \mathrm{~cm}$ in diameter, $160 \mathrm{~cm}$ in height, and $1.2 \mathrm{~cm}$ in thickness. The vessel is filled with demineralized light water used as both moderator and reflector. The core active part has the approximate shape of a cylinder of $100 \mathrm{~cm}$ in height and about $60 \mathrm{~cm}$ in diameter. It consists of two interlocked fuel zones with square lattices of different pitches:

- an inner zone of $336 \mathrm{UO}_{2}$ rods with an enrichment of $1.806 \mathrm{wt} . \%$ and a pitch of $1.837 \mathrm{~cm}$;

- an outer zone of $176 \mathrm{U}_{\text {metal }}$ rods for these experiments, $0.947 \mathrm{wt} . \%$ and $2.917 \mathrm{~cm}$; 
- a varying water gap between the two zones because of the two different pitches.

A picture of the reactor and its critical configuration are shown on Figure 1. Both uranium fuel rods consist of a 1-m pile of cylindrical pellets cladded in aluminum. The rods are maintained vertically by two octagonal aluminum grid plates spaced $1 \mathrm{~m}$ apart. In the current experimental configuration for the COLIBRI program [28]-[30], the grids have a $1-\mathrm{mm}$ cadmium layer to limit axial neutron leakage to the environment, i.e. structures activation, with the active zone of the fuel starting in the middle of the lower cadmium layer.

The neutron flux is monitored using two Merlin Gerin CC54 compensated ionization chambers (north and south), and two Photonis CFUM21 10-mg ${ }^{235} \mathrm{U}$ fission chambers (east and west), which are the calibrated power and safety monitors.

The reactor possesses six independent shutdown mechanisms to bring it to a subcritical state in less than one second: two cruciform cadmium $(\mathrm{Cd})$ safety blades in the inner zone, and four expansion tanks to drain the moderator, set in the vessel corners and controlled each by a valve. The safety systems are also used for shutdown under normal operation conditions.

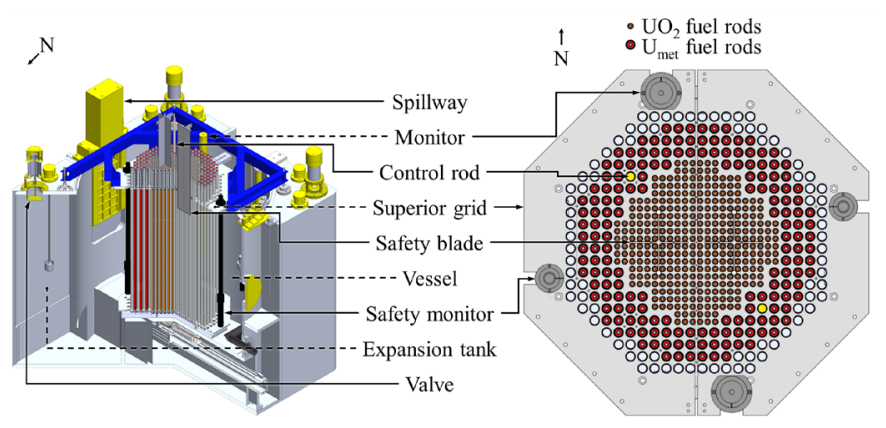

Fig. 1. Schematic isometric view of the CROCUS reactor (left), and top view of the core configuration (right).

\section{B. Methodology and experimental setup}

The used calibration methodology consists in three steps:

- in-core irradiation of dosimeters, monitored by the fission chambers to be calibrated,

- determination of the dosimeters' absolute activities with an High-Purity Germanium gamma spectrometer,

- simulation of the irradiation by Monte Carlo codes, to extract each dosimeter's reaction rate, and the corresponding fission rate, i.e. power of the reactor.

Gold dosimeters are employed as the ${ }^{197} \mathrm{Au}(\mathrm{n}, \gamma)$ cross section is a standard for neutron flux measurements in the thermal energy range, with a high cross section and low uncertainties [31]. In this study, 14 disc-form foil dosimeters with a diameter of $\varnothing 15 \mathrm{~mm}$, and a thickness of $10 \mu \mathrm{m}$ were used. For each irradiation, six dosimeters were axially distributed on a PMMA plate (see Figure 2). They are laminated in a plastic film to avoid deformation and contamination in the vessel's water.

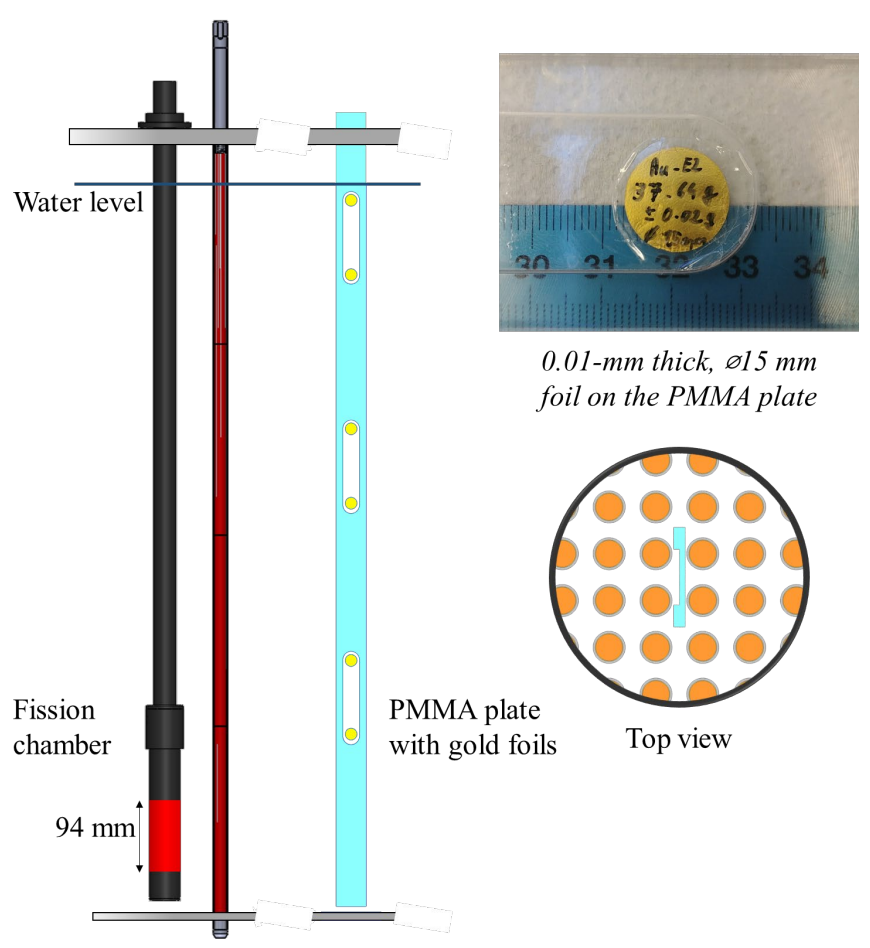

Fig. 2. On the left, schematic side view of one periphery fuel rod set in the superior and inferior grids, aside a monitor fission chamber with the active zone represented, and the PMMA plate inserted in the core. On the right, photo of a dosimeter set on the plate (top), and top view of the plate inserted in the lattice of the core inner zone.

The irradiation plate is positioned above the core center while the reactor is brought to criticality at the desired power by increase of the water level. Once the reactor is stabilized ( $\sim 10 \mathrm{~min}$ for the delayed neutron contribution), the plate is dropped in the core central axis. The enf-of-irradiation is a fast process, less than a second due to the safety systems, which also drain around half of the vessel's water. The dosimeters with the irradiation plate are recovered by opening the lid of the reactor's cavity immediately after the shutdown. Then, the dosimeters activities are measured one by one using a Canberra HPGe gamma spectrometer (detector: GC4518/S; shielding: VG-BB98/16D1-2). The HPGe detector is calibrated by a point-like calibration source of ${ }^{152} \mathrm{Eu}\left(\sigma_{\text {efficiency at } 411.8 \mathrm{keV}(\mathrm{Au})}=0.5 \%\right)$.

As the monitors' count rates are recorded during the irradiation, based on the measured activities and calculated reaction and fission rates, we derive the monitors' count rates per fission, or per unit of power.
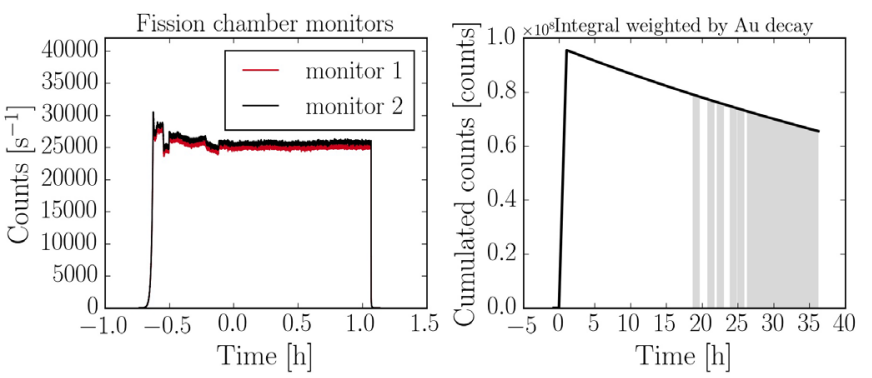

Fig. 3. Power history followed by both safety monitors (left), and computed activation with a representation of the foils' measurements on the HPGe station. $\mathrm{t}_{0}=0 \mathrm{~h}$ corresponds to the start of the irradiation (\#6). 


\section{Experimental campaign}

In order to investigate possible biases, as well as to quantify and reduce uncertainties, a set of irradiations was performed with selected repetitions and change of parameters (see Table I). All irradiations were carried out without control rods (guide tubes were left empty), so criticality was controlled only by changing the water level. At criticality, the PuBe start-up source is sent back to its storage shielding. This configuration allows the flux distribution to be as symmetrical as possible, without any local perturbations. The primary water-cooling circuit was engaged for at least one hour before the irradiation, in order to stabilize the water and temperature in the reactor vessel.

The irradiation in the reference configuration at $(20 \pm 0.1)^{\circ} \mathrm{C}$ was carried out three times at different power levels (10, 20 and $40 \mathrm{~W}$ ), and with different sets of dosimeters. One irradiation was performed with additional instrumentation in the reflector, in order to modify the critical water level. Two irradiations were accomplished in the reference configuration but at two different temperatures, at 18 and $22^{\circ} \mathrm{C}$, in order to assess the temperature dependence. A supplementary irradiation was undertaken at a subcritical level with a presence of the start-up source, at a water level of $800 \mathrm{~mm}$, to observe the deformation of the flux distribution.

TABLE I

EXPERIMENTAL CAMPAIGN

\begin{tabular}{ccccc}
\hline $\begin{array}{c}\text { Irradiation } \\
\#\end{array}$ & $\begin{array}{c}\text { Power } \\
{[\mathrm{W}]}\end{array}$ & $\begin{array}{c}\text { Duration } \\
{[\mathrm{s}], \pm 1 \mathrm{~s}}\end{array}$ & $\begin{array}{c}\text { Temperature } \\
{\left[{ }^{\circ} \mathrm{C}\right], \pm 0.1^{\circ} \mathrm{C}}\end{array}$ & $\begin{array}{c}\text { Critical level } \\
{[\mathrm{mm}], \pm 0.1 \mathrm{~mm}}\end{array}$ \\
\hline 1 & 9.7 & 3776 & 20.0 & 954.4 \\
2 & 20 & 4136 & 20.0 & 954.6 \\
3 & 40 & 1040 & 20.0 & 954.4 \\
4 & 10 & 3597 & 20.0 & 966.4 \\
5 & 10 & 3595 & 18.0 & 952.6 \\
6 & 10 & 3847 & 22.0 & 956.65 \\
7 & $\sim 3.10^{-3}$ & 17580 & 20.0 & 800.0 (subcrit.) \\
\hline \hline
\end{tabular}

\section{Monte CARlo CAlCUlations}

The irradiations were simulated with the MCNP6 and Serpent2 Monte Carlo codes, and using JEFF3.3 [32], ENDF/BVII.1 [33], and IRDFF-v1.05 [34] nuclear data libraries for comparison purposes. The detailed modelling included each individual dosimeter, and the water level of each irradiation. Models were used to compute reaction rates for each dosimeter at their location during the irradiation, and the reactor's fission rate. The reactor power was derived by multiplying the latter with the effective energy released per fission, and it was directly exectuted by the codes (e.g., for Serpent2, 3.245507 $10^{-11}$ $\pm 0.0025 \% \mathrm{~J} /$ fission $)$. In the case of the IRDFF library, the calculations were performed with Serpent 2 only, by replacing only the dosimetry cross sections. The use of the IRDFF gold files for propagating the uncertainties, for all foils axially distributed during one experiment, namely irradiation $\# 1$, from a cross section to individual reactions rates as a function of the neutron energy, is presented in Figure 4.
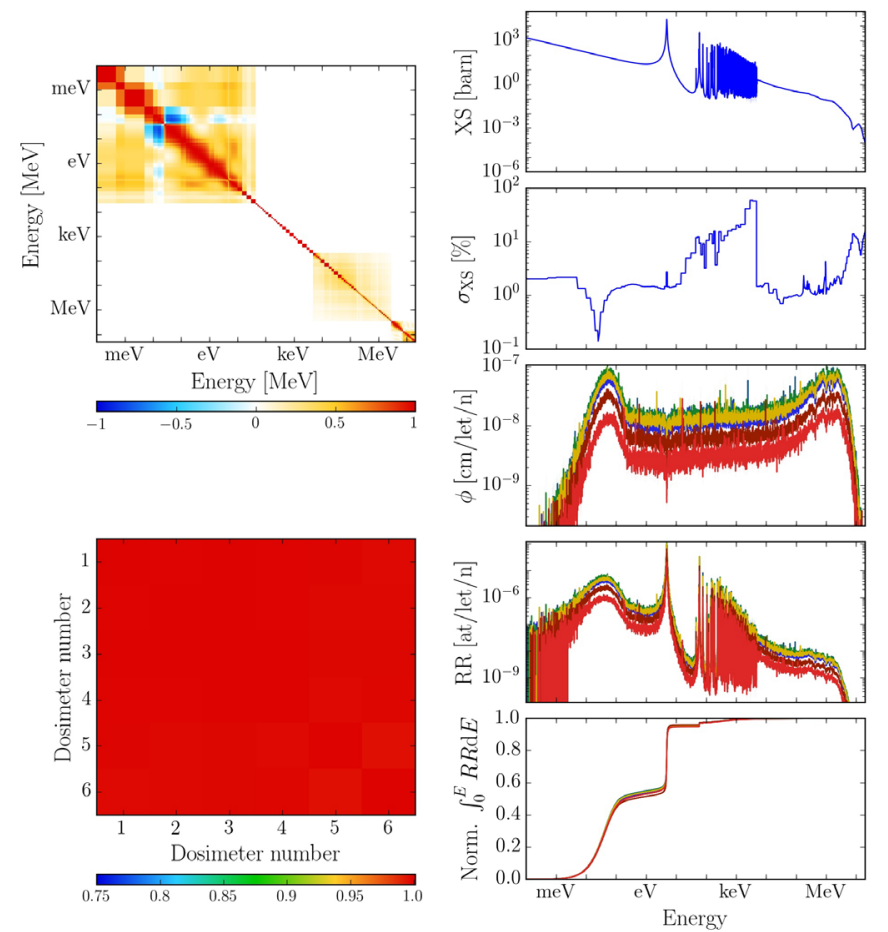

Fig. 4. Propagation of the IRDFF files for the ${ }^{197} \mathrm{Au}(\mathrm{n}, \gamma)$ reaction for uncertainty quantification of the reference irradiation $\# 1$. On the top left, covariance matrix according to the IRDFF library. On the bottom left, correlation matrix of the six dosimeters of the experiment, $100 \%$ correlated as expected. On the right, top to bottom, cross section, cross section uncertainty, computed spectra in the dosimeter, corresponding reaction rates as a function of the energy, and reactions rates integrated over the energy.

\section{RESULTS}

The experimentally determined reaction rates were averaged by weighting in order to calculate a single calibration factor for each monitor and irradiation. The dispersion has been used to estimate biases and uncertainties, but the results used by the facility are those from the first reference irradiation. As MCNP is the validated code for CROCUS by a regulatory body, the preliminary calibration factors based on MCNP6.2 with JEFF3.3 for the 2019 campaign are $(2708 \pm 54) \mathrm{cps} / \mathrm{W}$ for Monitor 1 (east) and $(2784 \pm 56) \mathrm{cps} / \mathrm{W}$ for Monitor 2 (west). The dosimeters at the top positions were discarded, as they present systematic errors, probably due to their position close to the water level. We observe a consequent shift in the distribution, which would require further investigation. For illustration purposes, the measured reaction rates are compared to the calculated ones using Serpent2 and JEFF3.3 with an arbitrary normalization in Figure 5.

Results obtained with the support of calculations with MCNP6.2 and Serpent2 are in a good agreement, in the order of their statistical uncertainty $\left(\sigma_{\mathrm{stat}}=0.5 \%\right)$. We observe a discrepancy of the order of $+1 \%$ between JEFF3.3 and ENDF/B-VII.1, which is low but still significant as compared to the statistical uncertainty $\left(\sigma_{\text {stat }}=0.2 \%\right)$. There is also a systematic discrepancy of $(+1.1 \pm 0.1) \%$ between JEFF3.3 with or without IRDFF for gold, when compared using Serpent 2 . 
TABLE II

RESULTS FOR MONITOR 1 DEPENDING ON CODE AND LIBRARY [CPS/W]

\begin{tabular}{|c|c|c|c|}
\hline Monte Carlo code & JEFF3.3 & $\begin{array}{l}\text { ENDF/ } \\
\text { B-VII.1 }\end{array}$ & $\begin{array}{l}\text { JEFF3.3 } \\
\text { +IRDFF }\end{array}$ \\
\hline MCNP6.1 & 2687.6 & 2659.1 & - \\
\hline Diff. /JEFF3.3 & 0 & $-1.1 \%$ & - \\
\hline Serpent2 & 2685.3 & - & 2714.8 \\
\hline Diff. /JEFF3.3 & 0 & - & $+1.1 \%$ \\
\hline Diff MCNP6.1/Serpent2 & $+0.1 \%$ & - & - \\
\hline
\end{tabular}

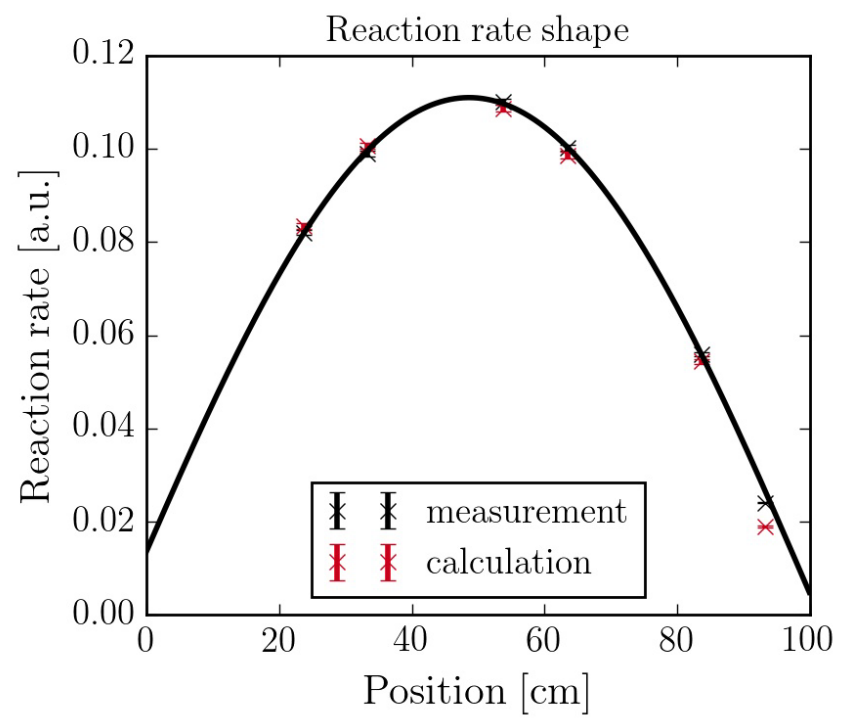

Fig. 5. Fitted axial distribution of the measured and calculated (Serpent2/JEFF3.3) reaction rates for the irradiation \#6.

\section{CONCLUSION AND OUTLOOK}

In the present article, we introduce the methodology used in CROCUS for the power calibration of the safety monitors. It is based on the in-core neutron dosimetry technique using the ${ }^{197} \mathrm{Au}(\mathrm{n}, \gamma)$ reaction for an activation analysis, complemented with detailed Monte Carlo calculations. For the 2019 calibration campaign, a set of irradiations was carried out to identify possible biases and quantify uncertainties. Preliminary calibration factors based on MCNP6.2 with JEFF3.3 are 2708 $\pm 54 \mathrm{cps} / \mathrm{W}$ for Monitor 1 (east) and $2784 \pm 56 \mathrm{cps} / \mathrm{W}$ for Monitor 2 (west). Good agreements were found between codes (within the low statistical uncertainties), as well as limited discrepancies between nuclear data libraries (in the order of $\%$ ). Further investigations shall include the understanding of discrepancies at the water-air interface, as well as the detailed study of temperature effects, and flux distributions at subcriticality.

\section{ACKNOWLEDGMENT}

The authors would like to thank the CROCUS operation team for the help and dedication to the experiments.

\section{REFERENCES}

[1] A. Rais, D. Siefman, G. Girardin, M. Hursin, and A. Pautz, "PARCS Few-group Homogenized Parameters Generation using Serpent Monte Carlo code at the CROCUS Reactor," in IGORR 2014, 2014, pp. $1-11$.

[2] M. Hursin, A. Rais, D. Siefman, G. Girardin, and A. Pautz, "Verification of a reactor physics calculation scheme for the CROCUS reactor," in International Technical Meeting on Small Reactors, 2014, pp. 3-8.

[3] O. Pakari, V. Lamirand, G. Perret, D. Godat, M. Hursin, P. Frajtag, and A. Pautz, "Investigation of spatial effects on neutron noise measurements in the zero power reactor CROCUS," in Proceedings of PHYSOR 2018, 2018, p. 12.

[4] V. Lamirand, G. de Izarra, A. Krasa, G. Perret, O. V. Pakari, M. Hursin, P. Blaise, J. Wagemans, and A. Pautz, "Intercomparison of neutron noise measurement systems in the CROCUS reactor," in Proceedings of PHYSOR 2018, 2018, p. 11.

[5] M. Hursin, C. Weiss, P. Frajtag, V. Lamirand, G. Perret, P. Kavrigin, A. Pautz, and E. Griesmayer, "Testing of a sCVD diamond detection system in the CROCUS reactor," Eur. Phys. J. A, vol. 54, no. 5, 2018. A. Laureau, V. Lamirand, D. Rochman, and A. Pautz, "Total Monte Carlo acceleration for the PETALE experimental programme in the CROCUS reactor," EPJ Web Conf., vol. 211, p. 03002, Jun. 2019.

[7] V. Lamirand, A. Laureau, D. Rochman, G. Perret, A. Gruel, P. Leconte, P. Blaise, and A. Pautz, "An Experimental Programme optimized with Uncertainty Propagation: PETALE in the CROCUS Reactor," EPJ Web Conf., vol. 211, p. 03003, Jun. 2019.

[8] Y. Jiang, A. Laureau, V. Lamirand, P. Frajtag, and A. Pautz, "In-core dosimetry for the validation of neutron spectra in the CROCUS reactor," in ANIMMA 2019, 2019.

[9] O. Pakari, V. Lamirand, B. Vandereyt, F. Vitullo, M. Hursin, C. Kong, and A. Pautz, "Design and simulation of gamma spectrometry experiments in the CROCUS reactor," in ANIMMA 2019, 2019.

[10] F. Vitullo, V. Lamirand, J.-B. Mosset, P. Frajtag, O. Pakari, G. Perret, and A. Pautz, "A miniature fiber-coupled scintillator for in-core neutron counting in CROCUS," in ANIMMA 2019, 2019.

[11] V. Lamirand, "Experiments in a ZPR in the 2010s : Harvesting data in CROCUS," in ANIMMA 2019 - Workshop $N^{\circ} 1$ "The coupling of experiments and modelling to enhance experiments in research reactors, " 2019.

[12] A. Rais, D. Siefman, G. Girardin, M. Hursin, and A. Pautz, "Methods and Models for the Coupled Neutronics and Thermal-Hydraulics Analysis of the CROCUS Reactor at EFPL," Sci. Technol. Nucl. Install., vol. 2015, 2015.

[13] D. J. Siefman, G. Girardin, A. Rais, A. Pautz, and M. Hursin, "Full Core modeling techniques for research reactors with irregular geometries using Serpent and PARCS applied to the CROCUS reactor," Ann. Nucl. Energy, vol. 85, pp. 434-443, 2015.

[14] V. Lamirand, M. Hursin, G. Perret, P. Frajtag, O. Pakari, and A. Pautz, "Future experimental programmes in the CROCUS reactor," in RRFM/IGORR 2016, 2016, no. 02-2016, pp. 284-292.

[15] A. Rais, M. Hursin, G. Perret, and A. Pautz, "Experimental validation of control rod reactivity worth and fission rate distributions for the CROCUS Reactor," Phys. React. 2016, PHYSOR 2016 Unifying Theory Exp. 21st Century, vol. 6, pp. 1-10, 2016.

[16] A. Rais, "Performance Assessment of a 3-D Steady-State and Spatial Kinetics Model for the Crocus Reactor," Ecole Polytechnique Fédérale de Lausanne (EPFL), 2017.

[17] O. Pakari, V. Lamirand, G. Perret, and A. Pautz, "Current Mode Neutron Noise Measurements in the Zero Power Reactor CROCUS," in ANIMMA 2017, 2017.

[18] O. Pakari, V. Lamirand, G. Perret, P. Frajtag, and A. Pautz, "Kinetic Parameter Measurements in the CROCUS Reactor Using Current Mode Instrumentation," IEEE Trans. Nucl. Sci., vol. 65, no. 9, pp. 2456-2460, 2018.

[19] V. Lamirand, G. Perret, S. Radman, D. Siefman, M. Hursin, P. Frajtag, A. Gruel, P. Leconte, P. Blaise, and A. Pautz, "Design of separated element reflector experiments in CROCUS: PETALE," React. Dosim. 16th Int. Symp. ASTM STP1608, p. 7, 2018.

[20] Ž. Štancar, L. Snoj, V. Radulović, A. Trkov, L. Barbot, and C. Domergue, "Evaluation of the Axial Absolute Power Profile Measurements at the JSI Triga Mark II Reactor," Nucl. Energy New Eur. 2012, no. October 2011, pp. 1-8, 2012.

[21] D. V. Ba, "Mesures absolues du flux neutronique et de la puissance 
du réacteur CROCUS par activation des feuilles d'or," 1971.

[22] P. Chartier, "Mesure de la puissance du réacteur CROCUS," 1974.

[23] R. Früh, "Réacteur CROCUS - Détermination de la puissance absolue," EPFL-IGA-LPR 179, 1990.

[24] J. F. Briesmeister and others, MCNP--A general Monte Carlo code for neutron and photon transport. Los Alamos National Laboratory Los Alamos, 1986.

[25] J. Leppänen, "Serpent--a continuous-energy Monte Carlo reactor physics burnup calculation code," VTT Tech. Res. Cent. Finl., vol. 4, 2013.

[26] U. Kasemeyer, R. Früh, J. M. Paratte, and R. Chawla, "Benchmark on Kinetic Parameters in the CROCUS Reactor," in International Reactor Physics Experiments Handbook (IRPhE), no. 4440, OECD, Ed. 2007, p. 94.

[27] J. M. Paratte, R. Früh, U. Kasemeyer, M. a. Kalugin, W. Timm, and R. Chawla, "A benchmark on the calculation of kinetic parameters based on reactivity effect experiments in the CROCUS reactor," Ann. Nucl. Energy, vol. 33, no. 8, pp. 739-748, May 2006.

[28] V. Lamirand, P. Frajtag, D. Godat, M. Hursin, G. Perret, O. V. Pakari, A. Laureau, A. Rais, C. Fiorina, M. Chadwick, and A. Pautz, "The COLIBRI programme in CROCUS: development and licensing of a fuel rods oscillator," in RRFM/IGORR 2019, 2019.

[29] V. Lamirand, P. Frajtag, D. Godat, M. Hursin, G. Perret, O. Pakari, A. Rais, C. Fiorina, and A. Pautz, "The COLIBRI programme in CROCUS : characterisation of the fuel rods oscillator," in ANIMMA 2019, 2019.

[30] V. Lamirand, A. Rais, S. Hübner, C. Lange, J. Pohlus, U. Paquee, C. Pohl, O. Pakari, P. Frajtag, D. Godat, M. Hursin, A. Laureau, G. Perret, C. Fiorina, and A. Pautz, "Neutron noise experiments in the AKR-2 and CROCUS reactors for the European project CORTEX," in ANIMMA 2019, 2019.

[31] B. Asselineau, F. Trompier, C. Texier, C. Itié, R. Médioni, D. Tikunov, H. Muller, and G. Pelcot, "Reference dosimetry measurements for the international intercomparison of criticality accident dosimetry SILENE 9-21 June 2002," Radiat. Prot. Dosimetry, vol. 110, no. 1-4, pp. 459-464, 2004.

[32] A. J. Koning, M. Avrigeanu, V. Avrigeanu, P. Batistoni, E. Bauge, M.-M. Bé, P. Bem, D. Bernard, O. Bersillon, A. Bidaud, O. Bouland, A. Courcelle, C. J. Dean, P. Dos-Santos-Uzarralde, B. Duchemin, I. Duhamel, M. C. Duijvestijn, E. Dupont, U. Fischer, R. A. Forrest, F. Gunsing, W. Haeck, H. Henriksson, A. Hogenbirk, T. D. Huynh, R. Jacqmin, C. Jouanne, J. Keinert, M. A. Kellett, I. Kodeli, J. Kopecky, H. Leeb, D. Leichtle, J. Leppanen, O. Litaize, M. J. Lopez Jimenez, M. Mattes, E. Menapace, R. W. Mills, B. Morillon, C. Mounier, A. L. Nichols, G. Noguere, C. Nordborg, A. Nouri, R. L. Perel, P. Pereslavtsev, R. J. Perry, M. Pescarini, M. Pillon, A. J. M. Plompen, D. Ridikas, P. Romain, Y. Rugama, P. Rullhusen, C. de Saint Jean, A. Santamarina, E. Sartori, K. Seidel, O. Serot, S. Simakov, J.-C. Sublet, S. Tagesen, A. Trkov, S. C. van der Marck, and H. Vonach, "The JEFF evaluated nuclear data project," pp. 3-8, 2008.

[33] M. B. Chadwick, M. Herman, P. Obložinský, M. E. Dunn, Y. Danon, A. C. Kahler, D. L. Smith, B. Pritychenko, G. Arbanas, R. Arcilla, R. Brewer, D. A. Brown, R. Capote, A. D. Carlson, Y. S. Cho, H. Derrien, K. Guber, G. M. Hale, S. Hoblit, S. Holloway, T. D. Johnson, T. Kawano, B. C. Kiedrowski, H. Kim, S. Kunieda, N. M. Larson, L. Leal, J. P. Lestone, R. C. Little, E. A. McCutchan, R. E. MacFarlane, M. MacInnes, C. M. Mattoon, R. D. McKnight, S. F. Mughabghab, G. P. A. Nobre, G. Palmiotti, A. Palumbo, M. T. Pigni, V. G. Pronyaev, R. O. Sayer, A. A. Sonzogni, N. C. Summers, P. Talou, I. J. Thompson, A. Trkov, R. L. Vogt, S. C. van der Marck, A. Wallner, M. C. White, D. Wiarda, and P. G. Young, "ENDF/B-VII.1 nuclear data for science and technology: Cross sections, covariances, fission product yields and decay data," Nucl. Data Sheets, vol. 112, no. 12, pp. 2887-2996, 2011.

[34] R. Capote, K. I. K. I. Zolotarev, V. G. V. G. Pronyaev, and A. Trkov, "Updating and Extending the IRDF-2002 Dosimetry Library," $J$. ASTM Int., vol. 9, no. 4, p. 104119, 2012. 